\title{
3 Research Suare \\ Challenges in Diagnosis of Food Allergies via Oral Food Challenges: A Qualitative Analysis of the Caregiver Perspective
}

\author{
Natasha Correa \\ Western University \\ Jennifer LP Protudjer \\ University of Manitoba
}

Elaine Hsu

The University of British Columbia

Lianne Soller

The University of British Columbia

\section{Edmond S Chan}

The University of British Columbia

Harold Kim

Western University

Samira Jeimy ( $\nabla$ jeimysb@gmail.com )

Western University https://orcid.org/0000-0002-3425-1874

\section{Research}

Keywords: Anaphylaxis, food allergy, food allergy diagnosis, focus groups, oral food challenge

Posted Date: September 4th, 2020

DOl: https://doi.org/10.21203/rs.3.rs-68765/v1

License: (c) (i) This work is licensed under a Creative Commons Attribution 4.0 International License. Read Full License 


\section{Abstract}

Background: Food allergy disproportionately affects children and contributes to poor quality of life for families. As a result, accurate diagnosis of food allergy is important. Oral food challenges (OFC) are the gold standard test for diagnosis of food allergy. Yet, many children do not undergo OFCs. The purpose of this study was to understand the barriers to OFCs faced by parents of children with food allergies in Ontario, as well as solutions to increase their utilization.

Methods: Three focus group discussions were carried out with a total of 24 parents of children with food allergies in Kitchener-Waterloo, Ontario. Focus group data were analyzed using constant comparative analysis.

Results: Parents misperceived OFCs as management of food allergies. They were also unsure about whether OFCs take place in hospitals, clinics or in the home. Parents reported several barriers to OFCs including not being referred by their primary care physicians, wait times, and fear and anxiety. Additionally, parents with older children, children with multiple allergies and children who could only tolerate allergens in its baked form felt that OFCs would not improve their quality of life. Solutions offered by parents to increase uptake of OFCs included education of the public, physicians and policy makers to improve knowledge and training, and ensure timely access to OFCs. Parents also suggested a need for improved counselling about the risk of OFCs, psychological support, and sharing of patient success stories. Long-term follow-up after an OFC as well as support and guidance around food reintroduction was also suggested to ensure OFCs resulted in an improvement in quality of life.

Conclusion: Interventions aimed at addressing barriers to OFCs identified by parents have the potential to increase utilization of OFCs, and thereby reduce the burden of food allergies in children and improve quality of life.

\section{Background}

Food allergy affects $6-7 \%$ of children in Canada (1). Families of children with food allergies have a poor quality of life (QOL). Food allergy lowers general health perception, limits activities, and has significant emotional (2-5) as well as economic effects on families (6). Given this impact, an accurate diagnosis of food allergy is critical.

Public misconceptions around food allergy diagnosis exist. Rates of self-reported food allergy are higher than those confirmed by physicians (7). Additionally, inappropriate and indirect methods of allergy testing result in misdiagnosis and an inflated prevalence of food allergies (8-12). Diagnosis of food allergy is based on clinical history and supportive testing, including skin prick testing (SPT) and food allergenspecific immunoglobulin (IgE). Because of the subjectivity of the clinical history, and of the low positive predictive values of SPT and IgE, an oral food challenge (OFC) is often necessary to confirm the diagnosis $(13,14)$. OFC involves gradual feeding of the suspected food with medical supervision for symptoms suggestive of IgE-mediated hypersensitivity $(15,16)$. 
Allergists and families may be hesitant to perform OFCs. A Canadian study out of British Columbia (BC) found that $81 \%$ of Canadian allergists perform OFCs and the median number of OFCs performed per month was 12 . However, nearly all allergists surveyed reported that there was a need to perform more OFCs. The same study also found that parents of children with food allergies face many barriers to OFCs including fear and anxiety about reactions, worry about child's anxiety and fear, ability to manage well despite allergy, and lack of knowledge about OFCs (17). Parental surveys and focus groups in this study were limited to parents living in BC. Studies from other countries report similar parental barriers to OFCs $(18,19)$. No previous studies have explored parental barriers to OFCs in other provinces in Canada. Ontario has the largest number of practicing allergists in Canada (20) but one of the lowest allergist billings for OFCs (21). The aim of this study was to assess perceived barriers to OFCs among parents of children with diagnosed food allergy in Ontario as well as solutions to increase use of OFCs.

\section{Methods}

\section{Participant recruitment}

English-speaking parents of children with allergist-diagnosed food allergies were recruited to participate in one of three focus groups. Each focus group consisted of 8 parents and was conducted between December 2017 and January 2018 in Kitchener-Waterloo, Ontario. Participants were recruited through office flyers in one of the author's (HK) allergy clinic. Focus groups were held at the same allergist's clinic. There were no honoraria provided. The study was approved by the BC Children's Hospital Institutional Review Board, which was amended to include the Ontario location.

\section{Focus group guide}

Focus group questions were developed based on review of the literature and expert opinions to capture parental attitudes and beliefs about OFCs. Questions centred around knowledge of the use of OFC for food allergy diagnosis, availability of OFCs, experiences with OFCs, factors impacting participation, barriers and solutions (Table 1 ). The same focus group questions were used in a previous mixed-methods study of barriers to OFCs in BC (17). 
Table 1

Focus group guide

\section{What does the term oral food challenge mean to you?}

2. Why would someone be told they need an OFC?

3. How often do you think allergists actually perform oral challenges?

4. Tell us about an experience your child had with an OFC.

5. What barriers can you think of that prevent your family from participating in an OFC?

6. What solutions might make it easier for your family to participate in one?

\section{Data collection}

Participants provided written informed consent. Participants also completed a questionnaire to collect demographic data and information about their children's food allergies. Investigators (SJ and HK) experienced and trained in leading focus groups guided the discussions. All focus groups lasted 2-3 hours and were audiotaped and transcribed verbatim by SJ. Data saturation was achieved by the end of the third focus group.

\section{Data analysis}

A constant comparative method was used to analyze focus group data (22). A coding scheme was developed within the framework of the main content domains based on focus group questions. Three authors (SJ, EH and NC) reviewed the transcripts and assigned codes to units of data based on ideas expressed by the participants. These lower order inductive codes were subsequently categorized into the higher order content domains. Codes were then aggregated into themes and compared across transcripts. Themes were modified and refined throughout the analysis process. Each author independently analyzed each transcript, then met to discuss and further refine their analysis. Discrepancies were reconciled until complete agreement was met. NVivo (version 12.6) (23) was used to code the interviews.

\section{Results}

\section{Participant characteristics}

Baseline demographics of focus group participants are shown in Table 2. Median age of participants was 41.5 years (interquartile range $35-47$ ), and $70.8 \%$ were female. Most participants had postsecondary education (87.5\%), and a household income above $\$ 100,000$ (66.6\%). Half (54.2\%) of the participants had children who had undergone OFC. Peanuts were the most common allergen (62.5\%). Ten parents $(41.6 \%)$ reported having children with multiple food allergies. 
Table 2

Demographic characteristics of participating parents and children

\begin{tabular}{|c|c|c|}
\hline & $\mathbf{n}$ & $\%$ \\
\hline \multicolumn{3}{|l|}{ Parent characteristics $(\mathrm{N}=24)$} \\
\hline Age in years, median (interquartile range) & \multicolumn{2}{|c|}{$41.5(35-47)$} \\
\hline Caucasian & 23 & 95.8 \\
\hline Female & 17 & 70.8 \\
\hline Family income $>\$ 100,000$ & 16 & 66.6 \\
\hline Post-secondary education & 21 & 87.5 \\
\hline Healthcare professional & 2 & 8.3 \\
\hline \multicolumn{3}{|l|}{ Child characteristics $(\mathrm{N}=24)^{a}$} \\
\hline \multicolumn{3}{|l|}{ Allergist diagnosis based on: } \\
\hline Skin prick test only & 5 & 20.8 \\
\hline Skin prick test $+\lg E$ & 4 & 16.7 \\
\hline Oral food challenge ${ }^{b}$ & 13 & 54.2 \\
\hline$\geq 2$ food allergies per child & 10 & 41.6 \\
\hline \multicolumn{3}{|l|}{ Type of food allergy ${ }^{c}$ : } \\
\hline Peanut & 15 & 62.5 \\
\hline Tree nuts & 7 & 29.2 \\
\hline Milk & 5 & 20.8 \\
\hline Egg & 4 & 16.7 \\
\hline Fish and shellfish & 3 & 12.5 \\
\hline Soy & 2 & 8.3 \\
\hline Sesame & 2 & 8.3 \\
\hline Other & 2 & 8.3 \\
\hline \multicolumn{3}{|c|}{ a Parents that reported having children with the listed characteristic } \\
\hline \multicolumn{3}{|c|}{ bIn combination with skin prick tests and/or lgE } \\
\hline${ }^{\mathrm{c}}$ Not mutually exclusive & & \\
\hline
\end{tabular}




\section{Themes}

The following themes and subthemes were identified.

\section{Theme 1 - Knowledge of OFCs}

\subsection{Parents perceived OFCs as necessary and understood the OFC process}

Parents reported that OFCs "are a necessary part of diagnosis," and "are probably the best confirmation of whether an allergy is there or not." Parents also stated that OFCs help "ascertain validity of other allergy tests." One parent stated that OFCs are done "if there are conflicting results - if the skin test says one thing and the blood test says another thing." Another parent reported that OFCs "can also be used to rule out false positive skin prick tests." Parents reported that other tests were used to determine whether and when to do an OFC:

"we did blood testing... the numbers were really high, so we didn't do it [OFC]. When the numbers dropped... we felt it was safe enough to go for it [OFC]."

Parents also knew that an OFC involves "starting with [the food in] small doses and increasing it at 20minute intervals." Parents stated that during an OFC there are "medical professionals who can deal with emergencies."

\subsection{Parents were uncertain about the purpose of OFCs and where OFCs take place}

Parents stated that OFCs would help "build up immunity to it [allergenic food" and it was "for them [children] to get used to it [allergenic food]." They "thought oral challenge... was desensitization."

Most parents reported that OFCs were conducted in a "controlled," "monitored," "supervised" and "medical" setting. However, some parents believed that "you have to go into a hospital," and that "many allergists don't like to do the challenges in clinic and nor should they." Parents reported that choice of setting was guided by severity of reaction and serum IgE levels:

"we are also going to the hospital this week because an egg reaction was more severe than the milk one."

"We knew from her bloodwork that the risk of a reaction was low. So, I felt comfortable being here [in clinic] doing it."

Other parents described instances where their doctor "suggested that it [OFC] would probably be okay to do at home."These parents felt uncomfortable with the idea of doing a home OFC or had negative experiences trying home OFCs.

\section{Theme 2 - Perceived Barriers to OFCs and Solutions}


The figure shows the relationship between perceived barriers and solutions to these barriers.

\subsection{Parents are frustrated with the lack of availability and access to OFCs, especially for young children}

Parents believed that "less than 5\% of allergists did [OFCs]." Some reported that OFCs were "never mentioned" by their allergist. Parents thought this lack of discussion may be because OFCs "are a new thing" and due to "liability" concerns. Those whose children had had OFCs described being "/ucky" to have an allergist who performed OFCs. Nonetheless, parents were frustrated by the long referral process and wait times. One parent reported having "to wait for an allergist's referral, and then to have to wait until the hospital has space, and the staff available." They wanted "more spaces in hospitals to accommodate timely OFCs."

Parents also experienced "a lot of pushback" from primary care physicians (PCP) to provide allergist referrals, especially for young children:

"we were not allowed to see an allergist before the age of 3 [years]."

One parent reported that her infant's symptoms of milk allergy were "brushed off" and attributed to "colic" by their PCP. As a result, parents wanted "education for family doctors and medical trainees" on the fact "that allergists can see kids sooner and intervene." Even after being referred to an allergist, parents reported receiving "conflicting medical advice" and experiencing "variation in different allergists practice" about doing OFCs. One parent was hesitant to undergo a peanut OFC because of a "previous allergist's opinion regarding severity of allergy."

\subsection{Although OFCs cause fear and anxiety, they can also alleviate these feelings}

Parents described OFCs as "nerve wracking." They feared the possibility of "having an unsuccessful oral challenge," "around use of Epipen $\Theta$," and "hav[ing] to go to emergency." Despite this, parents felt that OFCs could "take away the anxiety around 'may contain' and accidental ingestion." Parents also described dissipation of fear and anxiety if there was no reaction during the OFC:

"after the first quarter of a peanut when nothing happened it was fine."

Yet, parents felt that, "even if they have a reaction, there's probably some benefits of going through it [OFC]." To alleviate fear and anxiety parents wanted a "doctor [who] is experienced," "has access to skill and equipment," and "who would know what to do if something happened." They preferred to do the OFC in a place that is "set up for a real emergency." Other parents felt their OFC experience was "reassuring because we did it in the hospital." Experience with a previous successful OFC also reduced fear and anxiety during a subsequent OFC:

"with the baked milk my anxiety was higher. Because she was fine with that, the liquid milk was better."

Parents who had not experienced an OFC before wanted a platform to "share the success stories." Parents also wanted more information on "risk of challenge," and "what results of blood tests mean in 
terms of risk of challenge." They wanted this information from "knowledgeable health professionals" in the form of "written information" such as "FAQ on a credible website" as well as "frank discussion[s]" and "transparent communication" at appointments.

Parents described older children as "having a huge fear of [OFC]" which was attributed to "more knowledge of the consequences." Whereas the parent of a 3-year-old child reported, "she doesn't have the understanding to be fearful about it." Parents wanted strategies for "building confidence in children" and a "process to help with anxiety." One parent suggested "placebo-controlled challenges to help with issues around reacting based on anxiety."

\subsection{Parents required new coping skills for OFCs to improve QOL}

Parents reported that "some kids they don't want the food in the diet anyway" and "people are happy with the status quo if that have successfully avoided a food all their life." One parent described that even after a passing an almond and cashew OFC, "she still won't eat these foods - almonds tasted like wood."

Parents also described that OFCs were less important for foods that did not comprise a large part of the child's diet, did not offer much nutritional benefit and were potentially harmful. One parent reported that they did not do a peanut OFC because "there is significant mold, or aflatoxins." Conversely, foods that were ubiquitous in the diet were perceived to have a greater impact on QOL if ruled out as an allergen:

"we are hopeful of graduating into the world of dairy, because dairy is in everything."

OFCs were deemed to be important in improving the QOL of older children because parents "can't control their exposures forever. At some point they will leave the home, travel and live independently. It's better to find out earlier if there is a true allergy." Yet, older children were described as more resistant to doing OFCs:

"it was my pushing to do the OFC, not my son's. At age 14, the interest or compliance in wanting to do that is down. I felt like I missed a bit of my window."

Parents of children with multiple allergies stated that "if we could rule out some of them, then it could open up a bunch of options." However, for others a successful OFC did not always de-label their child:

"it may be easier to not introduce the food - explaining that one allergen is not an issue any longer, but other foods should still be avoided is difficult."

Parents with children who were undergoing baked food challenge stated that they were not "guided on the formulation [and] didn't have the information to start with baked egg."They were concerned about "the preparation that was required and the proper dosing." These parents also struggled with explaining the allergy to their child and community, thereby preventing reintroduction:

"I find it really difficult to explain her allergies to her. She can have baked but not liquid milk. We just tell the school there is a milk allergy." 


\section{Discussion}

Our study provides insights into parents' knowledge of OFCs, perceived barriers to OFCs, and solutions to barriers. Previous studies show that implementing solutions to improve OFC utilization is cost effective, compared to the economic burden of food allergies and the impact on QOL $(24,25)$.

Among parents of children with food allergies in BC, $41 \%$ reported lacking knowledge about OFCs (17). Our study reveals that OFC knowledge gaps stem from a misunderstanding of the purpose of OFCs as treatment of food allergies. In both Ontario and BC, parents wanted more information about OFCs. Parents were also unsure about where OFCs are conducted. Some parents felt strongly about not doing OFCs in clinics and homes whereas others were comfortable doing OFCs in either hospitals or clinics based on allergist recommendations and results of SPT and IgE. In BC, 91\% of parents chose OFCs conducted in hospitals as a moderately to extremely influential solution to mitigating barriers to OFCs (17). Parents in BC were recruited from a hospital-based allergy practice unlike parents in our study who were recruited from a community allergy clinic, which may explain differences in their opinions about OFC setting. In a survey of parents in New York, $17 \%$ reported trial of allergenic food at home as a reason for deferring OFCs (18). The American Academy of Allergy, Asthma and Immunology (AAAAI) recommends that OFCs be conducted in healthcare settings $(13,15,16)$. The British Society for Allergy and Clinical Immunology (BSACl) permits home challenges or reintroductions without challenges for children with milk and egg allergies under certain circumstances and provides instructions for parents on how to do so $(26,27)$. The SARS-CoV-2 pandemic has generated increasing interest in the use of telemedicine to conduct home-based virtual OFCs in low-risk scenarios (28). Given the importance of OFC setting for parents, parental discomfort with home OFCs and the risks associated with performing OFCs in healthcare settings during the SARS-CoV-2 pandemic, future studies could explore the utility and safety of home-based virtual OFCs. Improved knowledge of OFC among parents can be attained by disseminating information through national allergy associations on the purpose of OFCs as diagnosis of food allergy, various settings that OFCs can safely take place and criteria used to select OFC settings.

Parents reported that few allergists performed OFCs and that OFCs were difficult to access due to long wait times and limited resources. One study found that less than half of the allergists surveyed performed OFCs during fellowship training (29). Other studies show that although most allergists perform OFCs, they face multiple barriers including lack of time, insufficient reimbursement, risk of adverse event, lack of staff and lack of space $(17,29)$. Parents in our study had good insight into these barriers that allergists faced. Parents also reported hesitancy of PCPs to make allergist referrals for young children. One study found that only a quarter of PCPs knew that OFCs could be used to diagnose food allergies (30). In BC, the majority of allergists who performed OFCs did so in children including infants (17). However, only half of the pediatricians surveyed in BC reported being knowledgeable about OFCs - these pediatricians were more likely to refer to allergists who performed OFCs, but long wait times was a reason for not doing so (17). In Canada, the residency training curriculum for family medicine does not include food allergy diagnosis (31) whereas residency training for pediatrics does cover food allergy diagnosis including oral food challenges (32). As a result, there is a need for emphasis on food allergy training for primary care 
specialities, OFC training in allergy fellowships, and options for continuing medical education credits in food allergy diagnosis for physicians in practice.

Parents reported that OFCs gave rise to fear and anxiety, which were alleviated by a successful challenge. Several studies report fear and anxiety during OFCs among parents (17-19). Zijlastra et al., demonstrated resolution of parental anxiety after Double-blind placebo-controlled food challenge (DBPCFC) regardless of outcome. Additionally, parents who declined DBPCFC had higher levels of general anxiety trait than parents who accepted DBPCFC (33). Our study participants felt that OFCs are beneficial regardless of outcome and suggested a need for anxiety management solutions. The January 2020 update on conducting OFCs by the AAAAI includes a section on psychosocial considerations, calling for involvement of mental health professionals and implementation of anxiety management strategies (15). Other solutions for addressing fear and anxiety reported by parents in our study included offering DBPCFC, sharing of success stories by children and parents who have undergone OFCs, and emergency preparedness. No previous studies have examined whether parental anxiety differs between open versus blinded OFCs. DBPCFCs are time and resource intensive, and costly compared to open challenges but can help with distinguishing true allergy symptoms from those caused by anxiety (15), especially with use of delayed unblinding protocols (34). Future studies could look at whether blinded challenges reduce anxiety, and whether it would be cost effective to implement increased use of DBPCFC. Dissemination of information to parents on risks of OFCs and how emergencies are managed across various settings may also help alleviate fear and anxiety.

Previous studies report improved QOL among parents whose children underwent OFCs regardless of outcome (35). However, parents in our study were less likely to find the OFC impactful if the allergenic food was disliked, if their child had multiple allergies, and if the allergy was to milk or egg. In one study from New York, disinterest in the allergenic food was the most frequently cited reason for deferring OFCs (18). This was mostly reported by parents of older children in our study. As a result, older children were perceived as being less likely to reintroduce foods after being de-labelled than younger children. Previous studies report more successful reintroduction of foods and improved QOL for younger children than older children after passing an OFC $(36,37)$. Studies also demonstrate poor QOL among children with multiple allergies (37-39) and parents of children with milk or egg allergies (38, 40-42), both of which served as barriers to undergoing OFCs for parents in our study. As a result, there is a need for additional guidance and support for these families to help them translate the results of an OFC into everyday practicalities and thereby improve QOL. Additionally, studies also demonstrate diminishing improvement in QOL over time after an OFC (43), suggesting a need for long term support and guidance for all families.

\section{Strengths and Limitations}

The average duration of 2-3 hours per focus group suggests that participants had much to discuss about OFCs. Also, our observation that all participants had ample time to share individual opinions, rather than 
having a few dominant voices, speaks to the rigour of our data collection. Additionally, parents had a wide range of experiences with OFCs, yielding diverse opinions.

However, our study participants may not be representative of all parents across Canada for several reasons. Participants self-selected and may have been more knowledgeable about OFCs than most parents. Additionally, parents were selected from an allergist's referral base, and may have more severely food-allergic children. Also, all participants were patients of an allergist who performed OFCs. All participants were from Kitchener-Waterloo, a municipality in Southwestern Ontario with a strong university and technology-based economy. Additionally, participants were primarily Caucasian, female and economically advantaged. Finally, focus groups prevent detailed exploration of individual experiences, and views expressed may have been heard or learned instead of factors that personally influenced the participants.

\section{Conclusion}

This is the first qualitative study on perceptions of OFC amongst parents of children with food allergies in Ontario. Our findings mostly align with those found in BC (17), suggesting that major limitations to OFCs are independent of a healthcare system or patient cohort. In both Ontario and BC, parents expressed fear and anxiety and a need for psychosocial support. However, there were several unique insights provided by this study: parents from Ontario revealed misunderstanding about the purpose of OFCs, discomfort with home OFCs, a lack of allergist referrals for young children and held mixed views about how OFCs impact QOL. Until better treatments are developed, improving knowledge of food allergy diagnosis and implementing solutions to address the identified barriers to OFCs is our best option to mitigate the burden of food allergy on patients.

\section{Abbreviations}

BC - British Columbia

DBPCFC - Double-blind placebo-controlled food challenge

$\lg \mathrm{E}$ - Immunoglobulin E

OFC - Oral Food Challenge

PCP - Primary care physicians

QOL - Quality of life

SPT - Skin Prick Testing

\section{Declarations}




\section{Ethics approval and consent to participate}

Ethics approval was obtained from the British Columbia Children's Hospital Institutional Review Board. All study participants provided written, informed consent.

\section{Consent for publication}

Not applicable.

\section{Availability of data and materials}

The datasets used and/or analysed during the current study are available from the corresponding author on reasonable request.

\section{Competing interests}

JP sits on the steering committee of Canada's National Food Allergy Action Plan and performs research with DBV Technologies.

HK has been on speaker's bureaus and/or advisory boards for ALK, Aralez, Astra Zeneca, GSK, Kaleo, Mylan, Pediapharm, Pfizer, and Stallergenes Greer.

LS performs research with DBV Technologies.

ESC has received research support from DBV Technologies; has been a member of advisory boards for Pfizer, Pediapharm, Leo Pharma, Kaleo, DBV, AllerGenis, Sanofi Genzyme, Bausch Health; is a member of the healthcare advisory board for Food Allergy Canada; was an expert panel and coordinating committee member of the National Institute of Allergy and Infectious Diseases (NIAID)-sponsored Guidelines for Peanut Allergy Prevention; and was co-lead of the CSACl oral immunotherapy guidelines.

SJ has been on speaker's bureaus for Aralez, Novartis, Astra Zeneca, and Sanofi, and on the advisory board for Sanofi.

\section{Funding}

None.

\section{Authors' contributions}

SJ and HK performed data collection. SJ, EH, and NC performed data analysis. SJ and NC drafted the manuscript. SJ, HK, JP, EC, LS and EH contributed to study design and critical review of the manuscript. All authors read and approved the final manuscript.

\section{Acknowledgements}

We would like to thank all the participants of the focus groups in this study. 


\section{References}

1. Clarke AE, Elliott SJ, St. Pierre Y, Soller L, La Vieille S, Ben-Shoshan M. Temporal trends in prevalence of food allergy in Canada. J Allergy Clin Immunol Pract [Internet]. 2020;8(4):1428-1430.e5. Available from: https://doi.org/10.1016/j.jaip.2019.10.021

2. Sicherer SH, Noone SA, Muñoz-Furlong A. The impact of childhood food allergy on quality of life. Ann Allergy, Asthma Immunol. 2001;87(6):461-4.

3. Avery NJ, King RM, Knight S, Hourihane JOB. Assessment of quality of life in children with peanut allergy. Pediatr Allergy Immunol. 2003 Oct;14(5):378-82.

4. Bollinger ME, Dahlquist LM, Mudd K, Sonntag C, Dillinger L, McKenna K. The impact of food allergy on the daily activities of children and their families. Ann Allergy Asthma Immunol [Internet]. 2006 Mar [cited 2020 May 13];96(3):415-21. Available from: http://www.ncbi.nlm.nih.gov/pubmed/16597075

5. Primeau MN, Kagan R, Joseph L, Lim H, Dufresne C, Duffy C, et al. The psychological burden of peanut allergy as perceived by adults with peanut allergy and the parents of peanut-allergic children. Clin Exp Allergy. 2000;30(8):1135-43.

6. Protudjer JLP, Jansson S-A, Heibert Arnlind M, Bengtsson U, Kallström-Bengtsson I, Marklund B, et al. Household costs associated with objectively diagnosed allergy to staple foods in children and adolescents. J allergy Clin Immunol Pract [Internet]. 2015 Jan 1 [cited 2020 May 13];3(1):68-75. Available from: http://www.ncbi.nlm.nih.gov/pubmed/25577621

7. Nwaru BI, Hickstein L, Panesar SS, Roberts G, Muraro A, Sheikh A, et al. Prevalence of common food allergies in Europe: a systematic review and meta-analysis. Allergy [Internet]. 2014 Aug [cited 2020 May 13];69(8):992-1007. Available from: http://www.ncbi.nlm.nih.gov/pubmed/24816523

8. Jackson KD, Howie LJD, Akinbami LJ. Trends in allergic conditions among children: United States, 1997-2011. NCHS Data Brief. 2013;(121):1-8.

9. Sicherer SH, Muñoz-Furlong A, Godbold JH, Sampson HA. US prevalence of self-reported peanut, tree nut, and sesame allergy: 11-year follow-up. J Allergy Clin Immunol. 2010 Jun;125(6):1322-6.

10. Ben-Shoshan M, Kagan RS, Alizadehfar R, Joseph L, Turnbull E, St Pierre Y, et al. Is the prevalence of peanut allergy increasing? A 5-year follow-up study in children in Montreal. J Allergy Clin Immunol. 2009 Apr;123(4):783-8.

11. Bird JA, Crain M, Varshney P. Food allergen panel testing often results in misdiagnosis of food allergy. J Pediatr. 2015 Jan 1;166(1):97-100.e1.

12. Fleischer DM, Bock SA, Spears GC, Wilson CG, Miyazawa NK, Gleason MC, et al. Oral food challenges in children with a diagnosis of food allergy. J Pediatr. 2011;158(4).

13. Sampson HA, Aceves S, Bock SA, James J, Jones S, Lang D, et al. Food allergy: A practice parameter update - 2014. J Allergy Clin Immunol. 2014;134(5):1016-1025.e43.

14. Boyce JA, Jones SM, Rock L, Sampson HA, Cooper SF, Boyce S, et al. Guidelines for the diagnosis and management of food allergy in the United States: Report of the NIAID-sponsored expert panel. Vol. 126, Journal of Allergy and Clinical Immunology. Elsevier Ltd; 2010. 1-58 p. 
15. Bird JA, Leonard S, Groetch M, Assa'ad A, Cianferoni A, Clark A, et al. Conducting an Oral Food Challenge: An Update to the 2009 Adverse Reactions to Foods Committee Work Group Report. J Allergy Clin Immunol Pract [Internet]. 2020;8(1):75-90.e17. Available from: https://doi.org/10.1016/j.jaip.2019.09.029

16. Nowak-Wegrzyn A, Assa'ad AH, Bahna SL, Bock SA, Sicherer SH, Teuber SS. Work Group report: Oral food challenge testing. J Allergy Clin Immunol. 2009;123(6 SUPPL.).

17. Hsu E, Soller L, Abrams EM, Protudjer JLP, Mill C, Chan ES. Oral Food Challenge Implementation: The First Mixed-Methods Study Exploring Barriers and Solutions. J Allergy Clin Immunol Pract [Internet]. 2020;8(1):149-156.e1. Available from: https://doi.org/10.1016/j.jaip.2019.06.034

18. Davis N, Egan M, Sicherer SH. Factors resulting in deferral of diagnostic oral food challenges. J Allergy Clin Immunol Pract. 2015;3(5):811-812.e1.

19. Strinnholm Å, Brulin C, Lindh V. Experiences of double-blind, placebo-controlled food challenges (DBPCFC): A qualitative analysis of mothers' experiences. J Child Heal Care. 2010;14(2):179-88.

20. CMAJ. Clinical Immunology / Allergy Profile. Cmaj. 2018;(August).

21. Protudjer JLP, Soller L, Abrams EM, Chan ES. Billing fees for various common allergy tests vary widely across Canada. Allergy, Asthma Clin Immunol [Internet]. 2020;16(1):1-6. Available from: https://doi.org/10.1186/s13223-020-00426-0

22. Glaser BG, Strauss AL. The Discovery of Grounded Theory: Strategies for Qualitative Research. New York: Aldine De Gruyter; 1967.

23. Qualitative Data Analysis Software | NVivo [Internet]. [cited 2020 May 24]. Available from: https://www.qsrinternational.com/nvivo-qualitative-data-analysis-software/home

24. Couch C, Franxman T, Greenhawt M. The economic effect and outcome of delaying oral food challenges. Ann Allergy, Asthma Immunol [Internet]. 2016;116(5):420-4. Available from: http://dx.doi.org/10.1016/j.anai.2016.02.016

25. Alsaggaf A, Murphy J, Leibel S. Estimating Cost-Effectiveness of Confirmatory Oral Food Challenges in the Diagnosis of Children With Food Allergy. Glob Pediatr Heal. 2019;6.

26. Clark AT, Skypala I, Leech SC, Ewan PW, Dugué P, Brathwaite N, et al. British Society for Allergy and Clinical Immunology guidelines for the management of egg allergy. Clin Exp Allergy. 2010;40(8):1116-29.

27. Luyt D, Ball H, Makwana N, Green MR, Bravin K, Nasser SM, et al. BSACI guideline for the diagnosis and management of cow's milk allergy. Clin Exp Allergy. 2014;44(5):642-72.

28. Mack DP, Chan ES, Shaker M, Abrams EM, Wang J, Fleischer DM, et al. Novel approaches to food allergy management during COVID-19 inspire long-term change. J Allergy Clin Immunol Pract [Internet]. 2020;1-7. Available from: https://doi.org/10.1016/j.jaip.2020.07.020

29. Pongracic JA, Bock SA, Sicherer SH. Oral food challenge practices among allergists in the United States. J Allergy Clin Immunol. 2012;129(2):564-6. 
30. Gupta RS, Springston EE, Kim JS, Smith B, Pongracic JA, Wang X, et al. Food allergy knowledge, attitudes, and beliefs of primary care physicians. Pediatrics. 2010;125(1):126-32.

31. Assessment Objectives for Certification in Family Medicine | The College of Family Physicians of Canada [Internet]. [cited 2020 May 13]. Available from: https://www.cfpc.ca/en/educationprofessional-development/educational-frameworks-and-reference-guides/assessment-objectives-forcertification-in-fm

32. The Royal College of Physicians and Surgeons of Canada. Objectives of Training in Pediatrics. Object Train Pediatr. 2008;1-32.

33. Zijlstra WT, Flinterman AE, Soeters L, Knulst AC, Sinnema G, L'Hoir MP, et al. Parental anxiety before and after food challenges in children with suspected peanut and hazelnut allergy. Pediatr Allergy Immunol. 2010;21(2 PART 2):439-46.

34. Cook VE, To S, Soller L, Chan ES. Delayed Unblinding of Double-Blind Placebo-Controlled Food Challenges in Anxious Patients Allows Exclusion of Both Immediate and Delayed Adverse Reactions to Food. J allergy Clin Immunol Pract [Internet]. 2018;6(4):1432-3. Available from: https://doi.org/10.1016/j.jaip.2018.03.009

35. Franxman TJ, Howe L, Teich E, Greenhawt MJ. Oral food challenge and food allergy quality of life in caregivers of children with food allergy. J Allergy Clin Immunol Pract. 2015;3(1):50-6.

36. van der Valk JPM, van Wijk RG, Vergouwe Y, de Jong NW. Failure of introduction of food allergens after negative oral food challenge tests in children. Eur J Pediatr. 2015;174(8):1093-9.

37. Dunngalvin A, Cullinane C, Daly DA, Flokstra-De Blok BMJ, Dubois AEJ, Hourihane JB. Longitudinal validity and responsiveness of the Food Allergy Quality of Life Questionnaire - Parent Form in children 0-12 years following positive and negative food challenges. Clin Exp Allergy. 2010;40(3):476-85.

38. Howe L, Franxman T, Teich E, Greenhawt M. What affects quality of life among caregivers of foodallergic children? Ann Allergy, Asthma Immunol [Internet]. 2014;113(1):69-74.e2. Available from: http://dx.doi.org/10.1016/j.anai.2014.04.016

39. Allen CW, Bidarkar MS, Vannunen SA, Campbell DE. Factors impacting parental burden in foodallergic children. J Paediatr Child Health. 2015 Jul 1;51(7):696-8.

40. Abrams EM, Kim H, Gerdts J, Protudjer JLP. Milk allergy most burdensome in multi-food allergic children. Pediatr Allergy Immunol. 2020 May 15;

41. Ward CE, Greenhawt MJ. Treatment of allergic reactions and quality of life among caregivers of food-allergic children. Ann Allergy, Asthma Immunol [Internet]. 2015;114(4):312-318.e2. Available from: http://dx.doi.org/10.1016/j.anai.2014.12.022

42. Warren CM, Gupta RS, Sohn MW, Oh EH, Lal N, Garfield CF, et al. Differences in empowerment and quality of life among parents of children with food allergy. Ann Allergy, Asthma Immunol. 2015;114(2):117-125.e3.

43. Soller $L$, Hourihane J, Dunngalvin A. The impact of oral food challenge tests on food allergy healthrelated quality of life. Allergy Eur J Allergy Clin Immunol. 2014;69(9):1255-7. 


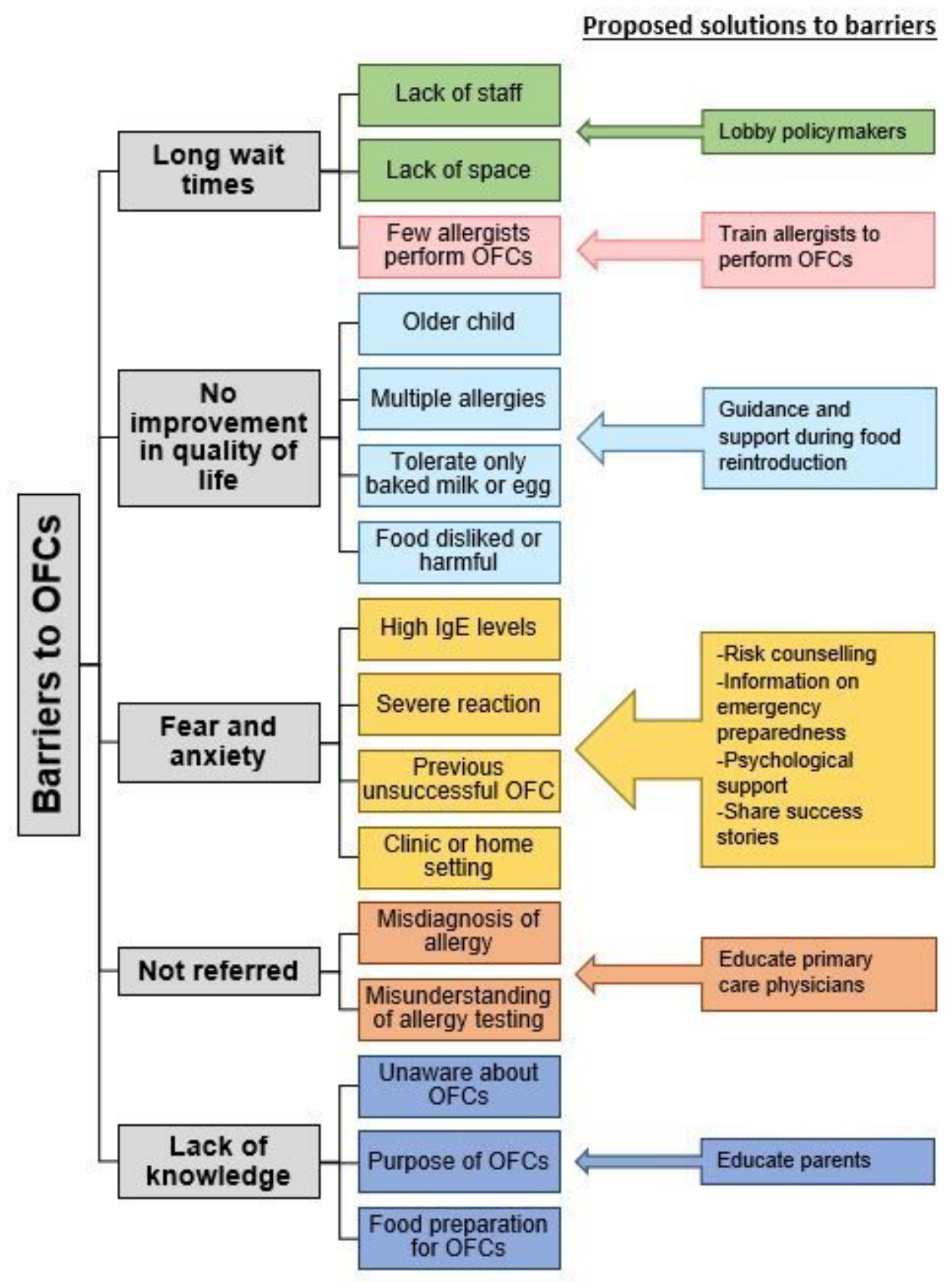

Figure 1

Perceived barriers to OFCs and solutions to barriers proposed by parents Colours represent barriers that fall under the same theme and its corresponding solution 